\title{
DETERMINISMOS CULTURAIS FRENTE À LUDICIDADE NA INFÂNCIA: CONCEITOS E CONCEPÇÕES PARADIGMÁTICAS
}

Jamily Charão Vargas ${ }^{1}$ Helenise Sangoi Antunes ${ }^{2}$

\section{Resumo}

Esta escrita contempla a temática da cultura instituída na sociedade e o espaço da infância ao longo dos tempos, discutindo a vivência das atividades lúdicas na primeira infância. Dessa forma, proporciona uma reflexão frente à percepção e à vivência da infância, estabelecida pela sociedade em cada tempo histórico. Utilizam-se autores como: Áries (1986) e Kramer; Leite (1998) para discutir a infância; Château (1987), Brougère (1995), Nogueira (1998), Santos (2000) e Negrini (2000) para a abordagem da prática lúdica e sua importância ao desenvolvimento infantil; bem como Morin (1991), Pérez Gómez (2001), Neves (2002) e Santos (2002) a fim de compreender os determinismos culturais na sociedade contemporânea, abordando aspectos da cultura escolar de hoje. Busca-se uma compreensão histórica de como a ludicidade está sendo vivenciada nos espaçostempos infantis e, mais especificamente, na escola. Assim, acredita-se nas práticas lúdicas como atividades relevantes e, mesmo necessárias, para um bom desenvolvimento infantil, salientando que estas devem estar presentes nas práticas educativas em tempos de avanços econômicos, tecnológicos e industriais.

Palavras-chave: Escola; ludicidade; infância; cultura; determinismo.

\footnotetext{
${ }^{1}$ Licenciada em Pedagogia pela Universidade federal de Santa Maria, Mestre em Educação pelo Programa de PósGraduação em Educação /UFSM (2010), professora da Rede Municipal de ensino de Foz do Iguaçu/PR e da Faculdade União das Américas. Endereço: Av. Florianópolis, n.1732. Bairro Jardim Santa Rosa. Foz do Iguaçu/ PR. CEP 85869010. Endereço eletrônico: vargas_mily@yahoo.com.br. Telefone Celular: (45) 99110335

${ }^{2}$ Licenciada em Pedagogia pela Universidade Federal de Santa Maria. Doutora em Educação, pela Universidade Federal do Rio Grande do Sul (2001). Atualmente é Professora Adjunto III, do Departamento de Metodologia do Ensino, do Centro de Educação, da Universidade Federal de Santa Maria. Endereço: Av. Nossa Senhora das Dores, n. 740 (fundos), Santa Maria/RS CEP: 97050-530. Endereço eletrônico: professora@helenise.com.br Telefone Residencial: (55) 32238018. Telefone Celular: (55) 91140360
} 


\begin{abstract}
Não se pode imaginar a infância sem seus risos e brincadeiras. Supúnhamos que, de repente, nossas crianças parem de brincar, que os pátios de nossas escolas fiquem silenciosos, que não sejamos mais distraídos pelos gritos ou choros que vêm do jardim ou do pátio, que não tivéssemos mais perto de nós este mundo infantil que faz a nossa alegria e o nosso tormento, mas um mundo triste de pigmeus desajeitados e silenciosos, sem inteligência e sem alma. Pigmeus que poderiam crescer, mas que conservariam por toda a sua existência a mentalidade de pigmeus, de seres primitivos. Pois é perto jogo, pela brincadeira que crescem a alma e a inteligência. É pela tranqüilidade, pelo silêncio - pelos quais às vezes os pais se alegram erroneamente - que se enunciam freqüentemente no bebê as graves deficiências mentais. Uma criança que não sabe brincar, uma miniatura de velho, será um adulto que não saberá pensar. (CHATEAU 1987, p.14)
\end{abstract}

Este artigo foi construído a partir de um diálogo entre a temática da pesquisa desenvolvida no curso de Mestrado em Educação do Programa de Pós-Graduação em Educação da Universidade Federal de Santa Maria ${ }^{3}$ e alguns tópicos que foram trabalhados na disciplina de Bases Epistemológicas da Educação ${ }^{4}$ do referido curso.

A pesquisa que resultou na construção da Dissertação de Mestrado foi realizada com o objetivo de analisar as concepções que alfabetizadoras de crianças de seis anos de idade (primeira infância) possuem frente à ludicidade na infância. Isso foi possível a partir de uma investigação de suas vivências lúdicas e das percepções que elas têm da infância no decorrer de suas trajetórias de vida pessoal e profissional.

Quando se pesquisam as práticas pedagógicas realizadas com crianças pequenas no decorrer de sua alfabetização, reflete-se sobre as estratégias e as metas para um trabalho docente de maior qualidade didática, que priorize o desenvolvimento pleno das crianças que compõe este nível de ensino. Neste momento, pensar a ação pedagógica significa voltar à atenção para o processo de aprendizagem infantil, para o bem-estar do aluno, respeitando as exigências da fase de desenvolvimento motor, psíquico, cognitivo, social e cultural.

Frente a isso, torna-se necessário pensar além dos conteúdos e técnicas a serem trabalhados na primeira infância, mas também, e principalmente, elaborar atividades que contemplam a infância

\footnotetext{
${ }^{3}$ Denominada "Professoras Alfabetizadoras e o Ensino Fundamental de nove anos: concepções frente à infância e à ludicidade".

${ }^{4}$ Especificamente os estudos que se referem à Morin (1991); Neves (2002); Santos (2002)
} 
e suas especificidades. Nesse sentido, trabalhar com a ludicidade, permitindo a livre expressão do esquema corporal, da curiosidade, da criatividade, da espontaneidade, da fantasia e da imaginação dos pequenos é muito importante.

Em estudos sobre a epistemologia educacional, algumas leituras instigam novos pensamentos e questionamentos frente a esta temática da "ludicidade na infância", o que contribui para o desenvolvimento desta reflexão. Deste modo, a pesquisa sobre as concepções de ludicidade na infância volta-se para alguns determinismos culturais influenciadores do modo das crianças viverem espaços e atividades lúdicas ao longo dos tempos. Assim, sabe-se que em diferentes épocas e culturas, foram construídas novas perspectivas para a abordagem da ludicidade e da infância, visto que, inerente a elas, estão os processos históricos e culturais da sociedade.

Compreende-se que não há possibilidade de pensar a ludicidade para crianças sem estudar a infância e os conceitos que a sociedade lhe atribuiu ao longo do tempo. Da mesma forma, também não se pode estudar a infância sem enfatizar as práticas lúdicas utilizadas nos diferentes tempos históricos e nas distintas culturas. Acredita-se que este movimento de estudar as infâncias e práticas lúdicas, permite compreender a cultura e história que permeiam as infâncias de hoje no Brasil. Entretanto, a maioria dos estudos existentes sobre as práticas lúdicas, até então, não costumam associá-las à cultura e à história da sociedade, o que seria bastante relevante e, mesmo, fundamental (BROUGÈRE,1995).

A história da evolução do brinquedo, das brincadeiras e dos jogos infantis, bem como a história da infância e dos conceitos que se atribui a ela, baseia-se na história e na cultura da sociedade. É importante que se entenda a infância como uma fase que nem sempre foi conceituada da maneira que é atualmente, podendo ser vista em diferentes perspectivas dependendo do tempo histórico, do lugar e da cultura em questão. Dessa forma, também a ludicidade, presente nessa fase da infância, sofre mudanças em seu conceito e concepções, mudanças estas determinadas pela época histórica e, principalmente, pela cultura da sociedade. 
Nesse sentido, segundo Morin (1991), para o indivíduo constituir-se e desenvolver seu conhecimento deve fazer parte de uma cultura, a qual é o ponto determinante na construção social. Assim, há um movimento recíproco, no momento em que a cultura determina o ser humano e é determinada por ele.

Torna-se relevante fazer uma breve descrição desta evolução histórica e influências culturais que perpassam a história da infância e da ludicidade, buscando compreender as formas, determinadas pelo âmbito social e cultural, de lidar com as crianças. Segundo Brougère (1995), no período histórico de Rousseau não era aceitável atribuir valor a comportamentos espontâneos originados pela própria criança, o que desvalorizava os atos lúdicos e, consecutivamente, a existência das práticas lúdicas.

Já durante o Romantismo, Brougère (1995) afirma que houve a exaltação e valorização dos comportamentos naturais das crianças pela sociedade, pois se enxergava neles uma verdade maior que aquelas provindas da razão por meio dos conhecimentos já constituídos. Nesse período, a sociedade passou a compreender a sociabilidade como destruidora de qualquer espontaneidade existente nas pessoas. Assim, houve uma total reavaliação do conceito de ludicidade, a qual passa a ser entendida como o "comportamento por excelência da criança".

Conforme Ariès (1986, p.275), ao comentar sobre a visão dos adultos perante a infância,

na idade média, no início dos tempos modernos, e por muito tempo ainda nas classes populares, as crianças misturavam-se com os adultos assim que eram consideradas capazes de dispensar a ajuda das mães ou das amas, pouco depois de um desmame tardio - ou seja, aproximadamente, aos sete anos de idade.

Nesta época, pode-se perceber que os paradigmas sociais dominantes eram diferentes, a família tinha uma função de, simplesmente, preparar para a vida sem a preocupação com a educação formal. Assim, a criança era percebida como um "pequeno adulto" e a infância como uma fase transitória de comportamentos espontâneos, mas que precisava ser apressada.

Os estudos de Brougère (1995) apontam que foi após o Romantismo que se passou a entender a ludicidade como algo não mais ligado apenas à aprendizagem espontânea. As práticas 
lúdicas não ocorriam mais unicamente de forma natural pela criança, mas como atividades lúdicas propostas ou induzidas, que buscavam instigar determinadas aprendizagens.

Segundo Kramer; Leite (1998, p.29) “o Iluminismo, em seu projeto de livrar os homens do mal que representa a ignorância ou o 'não saber' e torná-los senhores do mundo por meio da razão, inaugura num certo sentido, a preocupação com a criança e sua formação.” Inicia-se aí a preocupação da sociedade com a formação social da criança na perspectiva da educação formal. Assim, a partir de então, a escola passa a ser determinada como o meio de acesso à educação e não mais a aprendizagem informal.

Nota-se, ao longo das mudanças paradigmáticas em relação à infância e, concomitantemente, à ludicidade, que a criança deixa de ser vista apenas como um adulto em miniatura. Assim, a infância passou a ser compreendida como um período da vida a ser individualmente estudado e diferenciado das outras fases. Isso atribuiu um sentido maior para a existência da ludicidade na infância, para a valorização das práticas lúdicas como uma aliada para o desenvolvimento infantil e para a socialização da criança.

Novos paradigmas são determinados para a infância e para a ludicidade. Entende-se aqui por “paradigmas", o conceito apontado por Neves (2002, p. 36): “um conjunto de suposições teóricas gerais, de leis e técnicas adotadas por uma comunidade científica específica”, as quais prevalecem por um determinado período histórico.

Esses novos paradigmas provêm das novas tendências da sociedade atual, a qual passa por transformações muito rápidas no sentido da globalização e da união dos aspectos políticos, econômicos, sociais e culturais; destruindo as linhas divisórias entre eles, aceitando o pluralismo e a diversidade da sociedade contemporânea, bem como explorando a individualidade de cada povo e de cada cultura. Como afirma Pérez Gómez (2001, p. 28) “O respeito às diferenças pessoais, grupais ou culturais leva o pensamento pós-moderno à afirmação da tolerância, à aceitação teórica do 'outro', à justaposição cultural e, inclusive, à mestiçagem e interculturalismo". 
Assim, ao mesmo tempo em que há a comunicação, a articulação e o intercâmbio das diferentes culturas, há o respeito às individualidades destas culturas, não querendo a dominação de uma sob a outra. Nesse sentido, para Pérez Gómez (2001, p. 13):

O conceito de cultura popular se complica quando a evolução econômica, política e tecnológica estende seus horizontes a limites insuspeitos, de modo que os contextos de influências cotidianas e próximas se universalizam como consequiência da onipresença e do poder sedutor dos meios de comunicação de massa.

A partir da nova situação social que se configura devido à globalização, surgem novos conceitos de cultura, juntamente com os novos paradigmas emergentes. A cultura, agora, é estabelecida pelas mais diversas influências de hábitos, costumes, crenças, ideologias, vestimentas, culinárias, etc.

Nesse sentido, conforme Santos (2002, p. 18), "não se trata de um paradigma sócio-cultural global ou universal, mas sim de um paradigma local que se globalizou com êxito, um localismo globalizado". Segundo este autor, o paradigma da modernidade encontra-se em crise devido a muitos fatores, mas ele continua dominando devido à "inércia da história”. Assim, Santos (2002, p. 16) ressalta que vivemos em um tempo de transição de paradigmas, sendo que "A transição epistemológica ocorre entre o paradigma dominante da ciência moderna e o paradigma emergente que designo por paradigma de um conhecimento prudente para uma vida decente".

Assim, na tendência pós-moderna, fica para trás a preservação do que era universal e, no entanto, separava os distintos "reinos" (político, social, cultural, econômico). É uma nova época que surge a partir da teoria pós-industrial, fundamentada na sociedade da informação e a partir do pósfordismo, determinado pela descentralização e despadronização das formas de produção. O sujeito passa a valorizar o uso das tecnologias, a rapidez das informações e a conexão com o mundo, ao mesmo tempo em que busca aprimorar e aprofundar seus conhecimentos em áreas específicas.

Neste contexto, há a excessiva valorização da classe intelectual da sociedade, da dialética permeando as relações, as teorias, a formação de opiniões e as ações que se contradizem. Ao 
mesmo tempo em que há o excesso de informações, tornando o homem sujeito de sua própria história, há, também, a má utilização dessas informações.

Essa evolução leva à manipulação de novos aparelhos tecnológicos, novas formas de comunicação, novas tendências da moda, etc. A sociedade segue um ritmo coerente a esses avanços, fazendo parte deste mundo globalizado e capitalista, recebendo as informações mais rapidamente e estando sempre interligada através dos novos meios de comunicação. Nas palavras de Pérez Gómez (2001, p. 110):

Será necessário agora descer ao nível individual e detectar os efeitos novos no desenvolvimento do psiquismo das novas gerações, provocados por sua exposição a uma forma de viver e se relacionar, mediada esmagadoramente pela televisão e pelos meios de comunicação eletrônico (vídeo games, computador e vias da informação).

É importante entender toda a situação social, cultural, política e econômica em que a sociedade está inserida, pois todos estes aspectos influenciam diretamente na visão da sociedade em relação à infância e na vivência de práticas lúdicas. Às vezes, meio a tantas mudanças e informações, na tentativa de estarem atualizadas, as pessoas acabam valorizando em demasia estas tecnologias. Perante isso, surgem mudanças na vivência da ludicidade na infância, a partir da utilização da televisão, do computador, da internet, do vídeo game, entre outros.

O modelo econômico capitalista, que fortifica a ilusão do "ter" como principal aspecto para uma boa infância é uma realidade atual que influencia muito na nova configuração de infâncias atuais. A mulher, que antigamente tinha como atribuição cuidar da família e da educação dos filhos, hoje está inserida no mercado de trabalho para ajudar na renda da família. Com esta "emancipação" da mulher, também fortificou-se os índices de separação entre os casais, uma vez que a esposa não é mais uma submissa do marido.

Esta realidade é relevante e muito bem vista no que se refere às conquistas femininas na sociedade atual, no entanto, há famílias que não conseguiram conciliar tal realidade aos cuidados das crianças. São diferentes estruturas familiares e muitas vezes há sofrimento e descaso por parte da infância: crianças passam a ser criadas sem figura materna ou paterna, pelos pais em casas 
separadas e que as colocam um contra o outro, pelos avós ou tios que não possuem estrutura necessária ou, então, pelo casal de pais que brigam, discutem e até se batem na frente delas; crianças em tempo integral nas creches; crianças que ficam em casa sozinhas durante um turno ou todo o dia, olhando TV, jogando vídeo-game, conectando-se à internet ou fazendo outras atividades sem a mediação de adultos; ou crianças que são sobrecarregadas de atividades extracurriculares para ocuparem o tempo. Estes fatos, ocorridos em algumas realidades podem causar problemas à infância.

Para alguns pais é melhor que a infância passe depressa (Corazza, 2000). E, mesmo sem se dar conta, os adultos forçam seus filhos a não serem infantis em várias ocasiões: quando exigem comportamentos determinados, disciplinas rigorosas, participação na vida profissional e nos problemas financeiros e afetivos da família. Conforme Calderón (2009, p. 38)

Ao longo da década de noventa, diversos autores apontavam a existência de várias modalidades de família - além das famílias nucleares e mono-parentais reconhecidas pela Carta Magna - que paulatinamente vinham conquistando espaços e aceitação no cenário social e/ou no campo dos direitos humanos.

Assim, a infância passa por influências destas diferentes estruturações familiares que, hoje, são normais na sociedade. Percebe-se então que, a forma de compreender o período infantil na Modernidade fez com que a família se configurasse mais unida. No entanto, as mudanças do mundo contemporâneo ocasionaram mudanças nesta organização da família, levou a transformações nas concepções de infâncias e na maneira de lidar com elas. Nas evidências históricas mostram-se as diferenças nas infâncias vividas em tempos diferentes, pois sem tempo, espaço, amigos ou pessoas que os incentivem, as crianças deixam de brincar mais cedo que antigamente.

Também devido ao modelo econômico do capitalismo, é importante salientar que, cada vez mais, crescem as propagandas dos produtos, havendo maior manipulação dos consumidores através das imagens e do marketing, que trazem novidades que ultrapassam as necessidades primeiras do ser humano. Pérez Gómez (2001, p. 103) refere-se às propagandas políticas: 
A mediação publicitária da propaganda política chega a tal ponto que parece não existir mais realidade, mais política, mais líderes que os que aparecem na tela. A televisão tem a missão de definir a realidade e criar consenso em torno dela. As pessoas, de modo geral, já não fazem política, escutam-na.

Aproveitando esta consideração é relevante fazer uma analogia com os brinquedos, pois esta valorização da mediação publicitária da propaganda também ocorre no universo infantil. Assim, os brinquedos, objetos determinantes para a vivência da ludicidade, sofrem muitas influências da imagem que a propaganda lhes confere.

A valorização da imagem e as propagandas também provocam a crescente competitividade entre os produtos do mercado. Conforme Pérez Gómez (2001, p. 122),

na cultura da imagem que se impõe nas sociedades ocidentais pós-industriais, é incontível o domínio da aparência, o poder do efêmero e mutável, a ditadura do designer, das formas, da síntese à custa da comunicação aberta de significados, idéias, argumentos, discursos. As exigências do mercado na vida cotidiana e, em particular, por meio da publicidade audiovisual confundem cada vez mais profundamente o ser e o parecer (...).

É inevitável esta cultura de valorização da imagem e da propaganda atingir a infância, visto que as crianças estão influenciadas pela televisão e pela internet nas escolhas que podem fazer, escolhas estas que perpassam seus objetos de uso pessoal, como vestimentas, sapatos, materiais escolares e, principalmente, os brinquedos. Nessa direção, Pérez Gómez (2001, p. 96) também contribui afirmando que "o ritmo acelerado das mudanças no sistema de produção e consumo (...) estão provocando a desregulação da própria estrutura familiar tanto para a atenção dos menores como dos idosos", repercutindo outra visão da sociedade frente à infância, bem como outra forma de vivenciar a infância hoje.

Com isso, nessa sociedade, em que há uma organização articulada para a produção e o consumo de mercadorias, é normal a supervalorização dos brinquedos industrializados, sob a discriminação dos artesanais, visto que a industrialização dos brinquedos trouxe um novo enfoque para a ludicidade. Conforme Nogueira (1998, p.114),

“(...) a criança apropria-se da tecnologia pertencente ao mundo profissional adulto, transforma-a em brinquedo, aparelho-jogo, máquina lúdica, decretando a renovação de sua 
existência. Brinca de ser arquiteta, escritora, matemática, desenhista, bancária, fazendeira, imita os adultos em seus trabalhos."

Assim, as tecnologias trazem influências tanto negativas como positivas para a vivência da ludicidade na infância de hoje. Muitas vezes, as crianças acabam viciadas em jogos eletrônicos, desenhos animados ou computadores, deixando de fazer qualquer tipo de exercício físico ou mesmo deixando de se alimentar bem.

Por outro lado Brougère (1995 p. 53) aponta uma contribuição positiva, dizendo que "pela ficção, pelas diversas imagens que mostra, a televisão fornece às crianças conteúdo para suas brincadeiras." Nesse sentido, Brougère (1995, p.54), completa “o grande valor da televisão para a ludicidade na infância é oferecer às crianças, que pertencem à ambientes diferentes, uma linguagem comum, referências únicas”.

Também é importante destacar que a imagem do brinquedo traduz o desejo da criança ideal, ou desejo de ser adulto, remetendo a uma função social. Assim, as atividades lúdicas trazem aspectos peculiares da cultura do povo, pois, mesmo que inconscientemente, a criança representa a sociedade em que está inserida enquanto brinca.

Algumas práticas de brincadeiras são uma cópia da realidade vivida em cada época. Um exemplo é a boneca, que pode ser considerada um "espelho" da sociedade, mas um "espelho seletivo", que reflete determinados objetos, situações e realidades específicas da sociedade, não se detendo em estereótipos ou critérios diversos.

Cabe salientar, nesse sentido, a boneca "Barbie". Quantas meninas sonham em ser igual a Barbie? Ter o corpo, o cabelo, as roupas ou os sapatos dela? Ter um "Ken" de verdade? E esta boneca, tão preferida entre as meninas de diferentes idades, representa um estereótipo bastante seletivo, pois tem características e peculiaridades que definem um "perfil ideal" de mulher, moça, menina. 
Dentro desta nova configuração social, em que se desvelam novos contextos culturais e novos paradigmas sociais, configuram-se as novas perspectivas para a infância. Como aponta Negrine, (2000, p.21):

As mudanças decorrentes do mundo moderno vão progressivamente afastando os indivíduos do convívio lúdico (...). Os tempos modernos nos impõem outras formas de lazer, deslocando o eixo do lazer compartilhado com os outros para a forma de lazer individual.

A partir destas novas perspectivas, torna-se importante pensar como agir nos espaços de atuação pedagógica. É importante que os professores que trabalham com crianças comprometam-se com uma prática pedagógica coerente e sensível ao desenvolvimento infantil e à relevância da ludicidade para a aprendizagem na primeira infância. Mesmo que tenham surgidos novas concepções para a infância e a ludicidade, continua-se a acreditar nas práticas lúdicas como uma importante ferramenta para tornar a escola mais atraente e a aprendizagem mais significativa para as crianças.

Para trabalhar com a ludicidade na infância de hoje, deve-se pensar novas atitudes dos educadores frente às transformações sociais e culturais. Conforme Morin (1991), o conhecimento é produzido dependendo de fatores sociológicos, diretamente ligados à cultura. $\mathrm{O}$ autor (p. 20) coloca que uma cultura pode abrir ou fechar as potencialidades do conhecimento:

\footnotetext{
Ela as abre e atualiza fornecendo aos indivíduos o seu saber acumulado, a sua linguagem, os seus paradigmas, a sua lógica, os seus esquemas, os seus métodos de aprendizagem, de investigação de verificação, etc., mas ao mesmo tempo ela as fecha e inibe com suas normas, regras, proibições, tabus, o deu etnocentrismo, a sua auto-sacralização, a sua ignorância de sua ignorância. Ainda aqui o que abre o conhecimento é o que fecha o conhecimento.
}

Assim, a cultura, ao mesmo tempo em que produz muitos conhecimentos, normaliza na medida em que impede ou intimida a criação, agindo repressivamente e contribuindo para a manutenção dos hábitos já instituídos pela sociedade. Essas normas, regras e proibições ajudam na 
construção das verdades, certezas, valores e conceitos que formamos. Para expressar-se frente a esta realidade, Morin (1991) utiliza-se do termo Imprinting Cultural ${ }^{5}$.

Este Imprinting Cultural aprisiona o conhecimento diante do que está estabelecido pela sociedade, direcionando as ações dos sujeitos. Conforme Morin (1991, p.30), ele "inscreve-se cerebralmente desde a mais tenra infância pela estatização seletiva das sinapses, inscrições iniciais que marcarão irreversivelmente o espírito individual no seu modo de conhecer e agir”. Dessa forma, somos culturalmente invadidos por normas desde a infância, o que pode vir a impedir o desenvolvimento de atitudes espontâneas, autônomas e criativas no indivíduo, sendo este submetido a atitudes instituídas pela família, escola, grupos sociais, amigos, etc.

Essas normas atuam fortemente nas práticas dos indivíduos em relação à ludicidade. Como salienta Santos (2000, p.57):

Culturalmente somos programados para não sermos lúdicos. Basta lembrarmos quantas vezes em nossas vidas já ouvimos frases como estas: "Chega de brincar, agora é hora de estudar"; "Brincadeira tem hora"; "Fale a verdade, não brinque"; "A vida não é uma brincadeira". Assim fomos construindo nossas idéias sobre o lúdico.

A desvalorização da ludicidade não é determinada por outro elemento se não pelas histórias e culturas da sociedade. E as características de espontaneidade, autonomia e criatividade são, exatamente, o que a ludicidade proporciona àqueles que a vivenciam. É importante que a sociedade não limite-se apenas ao conhecimento determinado pelas normas e regras culturalmente impostas. Ela deve buscar condições de libertação deste conhecimento, autonomia do pensamento e inovações nos domínios culturais, sociais e históricos para proporcionar uma maior reflexão perante a infância que queremos nesta nova sociedade que se impõe através de novos paradigmas.

Sabe-se que a escola e a família, espaços onde as crianças vivenciam sua infância, está impregnada por paradigmas históricos e culturais e que as mudanças surgidas ao longo dos tempos

\footnotetext{
${ }^{5}$ Baseado em Konrad Lorent, que o utilizou para definir o ato intuitivo do passarinho, que atribui papel de sua mãe ao primeiro ser que enxerga. Segundo Morin (1991), como o passarinho, nossas ações no mundo já estão marcadas pelo "selo da cultura" das pessoas que já o habitam.
} 
vêm os modificando, o que, concomitantemente, modifica as infâncias e práticas lúdicas. No entanto, não basta olhar estas mudanças, refletir sobre elas, compreendê-las e estudá-las.

Mais que isto, neste momento histórico de aceleração das relações virtuais e dos programas sedentários que fazem da televisão e do computador os maiores e, por vezes, únicos companheiros das crianças, é preciso uma atitude de pensar que infância se quer e o que pode estar prejudicando o mundo infantil. É possível ver os avanços industriais, tecnológicos e sociais como aliados para um melhor desenvolvimento infantil, mas para que isso ocorra não se pode deixar que problemáticas como o sedentarismo, a má alimentação, obesidade, a ausência da figura materna ou paterna e o excesso de tempo dispensado aos programas virtuais prejudique as crianças.

É preciso pensar a infância para além destas mudanças sociais e culturais. Dessa forma, deixam-se aqui algumas reflexões que os educadores precisam incorporar, a fim de entender e repensar a infância e a ludicidade neste novo cenário, buscando uma reconstituição de práticas que sejam eficazes para o bom desenvolvimento infantil atualmente. Acredita-se e aposta-se que a permanência e fortificação da ludicidade, do movimento, da criatividade, da espontaneidade e autonomia infantil seja um caminho possível. Diante disso, remete-se às contribuições de Elkind (2004, p.240)

\footnotetext{
Não importa que filosofia de vida abracemos, é importante encarar a infância como um estágio da vida, não simplesmente como a ante-sala da vida. Pressionar as crianças para serem adultas viola a santidade da vida, priorizando um período em detrimento de outro. Mas se realmente valorizarmos a vida humana, vamos valorizar cada período igualmente e dar a cada estágio da vida o que é adequado a este estágio.
}

E o que é adequado à infância? Está-se proporcionando às crianças uma boa infância em meio aos novos determinismos histórico-culturais? É comum escutar adultos falar: "aproveite, pois esta é a melhor fase da vida”. Que contraditório, pois nem sempre são dadas as condições para que aproveitem esta fase, nem mesmo para que a vivenciem. Como as crianças poderão aproveitar, meio a tantas atividades e deveres que a sociedade atual lhe impõe? Como irão ser crianças se seus direitos muitas vezes são negligenciados pelas diversas formas de violências contra a infância? De 
que forma irão brincar livremente se só podem ficar dentro da casa ou do apartamento? Como não seguir a mídia, se esta as apresenta propostas inegáveis aos olhos infantis? De que forma se portar como crianças se são "treinadas" desde cedo para serem adultos? Então, quem pode, na sociedade de hoje, ter o privilégio de ter uma infância e viver práticas lúdicas?

A preocupação com estas infâncias e com a valorização de atividades lúdicas para que a criança não perca sua identidade precisa ser presente entre os educadores. Não se pode mudar esta realidade da sociedade que transforma o brinquedo, a brincadeira e o jogo infantil, mas ainda se pode refletir a construção destes brinquedos para que a ludicidade contemporânea, pensada numa perspectiva histórico-cultural, não deixe de privilegiar o desenvolvimento da criatividade, movimento, autonomia e imaginação da criança.

\section{CULTURAL DETERMINISMS IN FRONT OF CHILDHOOD PLAYFULNESS: CONCEPTS AND PARADIGMS}

\section{Abstract}

This paper aims the culture instituted in the society and the childhood space during the years, discussing the play activities in the first childhood. In this way, it provides a reflection about the perception and experiences in childhood, established by society in a specific historical time. It was used authors as: Áries (1986) and Kramer; Leite (1998) to discuss the childhood; Château (1987), Brougère (1995), Nogueira (1998), Santos (2000) and Negrini (2000) to the approach of childhood aspects and its importance to children development; and Morin (1991), Pérez Gómez (2001), Neves (2002) and Santos (2002) to understand the cultural determinisms in contemporary society, considering aspects of actual school culture. It purposes the historical comprehension of how the playfulness is being lived in the children spaces-times, and more specific, in the school. Then, it's believed in playfulness experiences as relevant activities and necessary to good children 
development, emphasizing that the playfulness activities must be present in the pedagogical practices in time of economic, technological and industrial advances.

Keywords: School; playfulness; childhood; culture; determinism.

\section{Referências}

ARIÈS, Philippe. História Social da Criança e da Família./ Philippe Áries; tradução Dora Flaksman. $2^{\circ}$ ed. - Rio de Janeiro: Guanabara, 1986.

BROUGÈRE, Gilles. Brinquedo e Cultura./ Gilles Brougère; revisão técnica e versão brasileira adaptada por Gisele Wayskop. - São Paulo: Cortez, 1995. (coleção questões da nossa época, v.43).

CALDERÓN, Adolfo Inácio. As mudanças na família e seus reflexos nas políticas de proteção as crianças e adolescentes. In.: FOSSATI, P.; PAULY, E.L.; MEZA, C.J.D. (orgs). Criança e adolescente: sujeitos de direitos humanos. Canoas, RS: Salles, 2009.

CHÂTEAU,Jean. O jogo e a criança./ Jean Château; tradução Guido de Almeida. - São Paulo: Summus, 1987. (novas buscas em educação; v. 29).

ELKIND, David. Sem tempo para ser criança: a infância estressada. David Elkind/ trad. Magda França Lopes. - $3^{\text {a }}$ Ed. - Porto Alegre: Artmed, 2004.

KRAMER, Sonia; LEITE, Maria Isabel Ferraz Pereira. Infância e produção Cultural./ orgs. Sonia Kramer e Maria Isabel Leite. Campinas, SP: Papirus, 1998. (série prática pedagógica).

MORIN, Edgar. Determinismos culturais e efervescências da cultura. In.: MORIN, Edgar. O método IV. 1991

NEGRINE, Airton. O Lúdico no Contexto da Vida Humana: da primeira infância às terceira idade. In SANTOS, Santa Marli Pires dos. (org.). Brinquedoteca: a criança, o adulto e o lúdico. Petrópolis, RJ: Vozes, 2000.

NEVES, Marcos Cezar Danhoni. Lições da escuridão ou revisitando velhos fantasmas do fazer e do ensinar ciência. São Paulo: Mercado de Letras, 2002. 
NOGUEIRA, Letícia. Imagens da criança no computador. In. : KRAMER, Sonia; LEITE, Maria Isabel Ferraz Pereira. Infância e produção Cultural./ orgs. Sonia Kramer e Maria Isabel Leite. Campinas, SP: Papirus, 1998. (série prática pedagógica).

PÉREZ GÓMEZ, A. I. A cultura escolar na sociedade neoliberal / A. I. Pérez Gómez; trad. Ernani Rosa. - Porto Alegre: ARTIMED Editora, 2001.

SANTOS, Santa Marli Pires dos. (org.). Brinquedoteca: a criança, o adulto e o lúdico. Petrópolis, RJ: Vozes, 2000.

SANTOS, Boaventura de Souza. A crítica da razão indolente: contra o desperdício da experiência, Vol. I, p. 13 - 117. In.: SANTOS, Boaventura de Souza. Para um novo senso comum - A ciência, o direito e a política da transição paradigmática. - 4 ed. - São Paulo: Cortez, 2002.

Data de recebimento: $15 / 11 / 2008$

Data de aceite: 29/07/2010 